\title{
Enzyme Defect in a Case of Tyrosinemia Type I, Acute Form
}

\author{
NOBUAKI FURUKAWA, AKIHIKO KINUGASA, TOMOKO SEO, TAKASHI ISHII, TOMOO OTA, \\ YUKIYASU MACHIDA, FUMIO INOUE, SHINSAKU IMASHUKU, TOMOICHI KUSUNOKI, AND \\ TETSURO TAKAMATSU
}

Department of Pediatrics [N. F., A. K., T. S., T. I., T. O., Y. M., F. I., S. I., T. K.] and Department of Pathology

[T. T.], Kyoto Prefectural University of Medicine, 602, Kyoto, Japan

\section{Summary}

We determined the activities of tyrosine aminotransferase (TAT, EC 2.6.1.5), $p$-hydroxyphenylpyruvate oxidase (p-HPPA oxidase, EC 1.14.2.2) and fumarylacetoacetate fumarylhydrolase (FAH, EC 3.7.12) in cytosol of the liver and kidney tissues obtained at autopsy from a case of hereditary tyrosinemia type I. Values were compared with those from a control group of autopsied tissues from three adults and six children, who had died of other causes. In tyrosinemia, these three hepatic enzyme activities were all decreased: TAT showed approximately $35 \%$, p-HPPA oxidase $11 \%$, and FAH $60 \%$ of the corresponding control values. On the other hand, kidney enzymes in tyrosinemia revealed that FAH was most significantly decreased to approximately $14 \%$ of the control activity. $K_{m}$ values for substratedetermined for p-HPPA oxidase and FAH-were not different between the patient and controls, suggesting no altered properties of these enzymes. We conclude that in the present case of hereditary tyrosinemia type I, the activities of p-HPPA oxidase in liver and FAH in kidney were most strikingly affected. This fact may in part explain the deteriorated metabolism of tyrosine observed in this patient.

\section{Abbreviations}

FAH, fumarylacetoacetate fumarylhydrolase p-HPPA, p-hydroxyphenyl-pyruvate

TAT, tyrosine aminotransferase

Hereditary tyrosinemia type I, acute form, is an autosomal recessive disorder characterized by failure to thrive, hepatic dysfunction, hypoglycemia, and renal tubular dysfunction. The plasma levels of tyrosine and methionine are markedly elevated and there is increased urinary excretion of tyrosyl compounds (tyrosine, $\mathrm{p}$-HPPA, p-hydroxyphenyllactate, and p-hydroxyphenylacetate). The excessive excretion of phenolic acids has led some investigators $(12,21)$ to suggest that the enzyme, p-HPPA oxidase, is involved in the pathogenesis of this disorder. In fact, several authors $(15,23)$ confirmed that the p-HPPA oxidase activity was markedly reduced in the liver of patients; this was once considered to be a primary defect, but still is controversial $(2,8)$.

There is now strong speculation that the defect in fumarylacetoacetate degradation may be a leading cause of tyrosinemia type $I(1,11,14,17)$. But it is not yet known whether this defect is the primary cause of this disease. To elucidate whether or not the disease is an inborn error with two enzyme defects, it is necessary to examine not only FAH but also p-HPPA oxidase simultaneously in the patient's liver. In addition, studying these enzyme activities in both the kidney and the liver may shed light on the role of the kidneys in the altered tyrosine metabolism in this disorder.

\section{CASE REPORT}

The patient, a male infant, weighing $1700 \mathrm{~g}$ was born at 31 wk gestation to a 23-yr-old mother who had mild hyperthyroidism. There was no consanguinity between the parents, and a normal female had been born 14 mo previously. The patient was admitted at $1 \mathrm{~d}$ of age with severe jaundice and petechiae over the entire body. The serum concentration of bilirubin rose to $24.0 \mathrm{mg} / \mathrm{dl}$ with $11.5 \mathrm{mg} / \mathrm{dl}$ direct. The hepatitis B surface antigen test was negative. The SGOT was 444 IU, the SGPT was 270 IU, the alkaline phosphatase $32.8 \mathrm{IU}$. The serum concentration of calcium was $7.9 \mathrm{mg} / \mathrm{dl}$, blood urea nitrogen $14.4 \mathrm{mg} / \mathrm{dl}$, and glucose $41 \mathrm{mg} / \mathrm{dl}$. Titers for rubella, herpes, and cytomegalovirus were not increased. At 1,2, and $6 \mathrm{~d}$ of age he was treated with exchange transfusion. Serum bilirubin had decreased only transiently in response to exchange transfusion, and subsequently increased up to $38.9 / 25.9 \mathrm{mg} / \mathrm{dl}$ at $\mathrm{d} 18$ (Fig. 1). He had intermittent apnea. Carcinoembryonic antigen was $2.2 \mathrm{ng} / \mathrm{ml}$. Alpha-fetoprotein was above $320 \mathrm{ng} / \mathrm{ml}$. At $17 \mathrm{~d}$ of age, his serum tyrosine was found to be extremely high, $13.1 \mathrm{mg} / \mathrm{dl}$, and the concentration of methionine was $3.1 \mathrm{mg} / \mathrm{dl}$. At this time, urinary tyrosine metabolites (p-HPPA, p-hydroxyphenyllactate, and $p$-hydroxyphenylacetate), glycine, threonine, tyrosine, and serine were markedly increased (Table 1$)$. Treatment was begun with vitamin $C(100 \mathrm{mg} / \mathrm{d})$ and a low phenylalanine $(13 \mathrm{mg}$. $\left.\mathrm{kg}^{-1} \cdot \mathrm{d}^{-1}\right)$ low tyrosine $\left(13 \mathrm{mg} \cdot \mathrm{kg}^{-1} \cdot \mathrm{d}^{-1}\right)$ formula, but he showed no clinical improvement. The diet produced a remarkable fall in serum tyrosine, accompanied by a rise in methionine (Fig. 1). At $27 \mathrm{~d}$ of age, the patient developed acute dyspnea, rapidly became comatose, and died. An autopsy revealed extensive hepatic fibrosis and bile duct proliferation surrounding the nodules. There was no remarkable change in pancreatic islets. The renal tubuli were moderately dilated.

\section{MATERIALS AND METHODS}

Amino acids in serum were determined with high performance liquid chromatography (Shimazu-LC-3A). Organic acids in urine were identified and quantitated by gas chromatography-mass spectrometry-computer techniques through the courtesy of Dr. I. Matsumoto (19). Liver and kidney specimens were obtained from the patient within $4 \mathrm{~h}$ after death, and stored at $-80^{\circ} \mathrm{C}$ until used. Control specimens were obtained from three adults and five children at autopsy and stored as described above. Except for two cases (control B and $\mathrm{H}$ in Table 2), all control patients showed moderate to severe liver dysfunction (Table 2, footnote). 


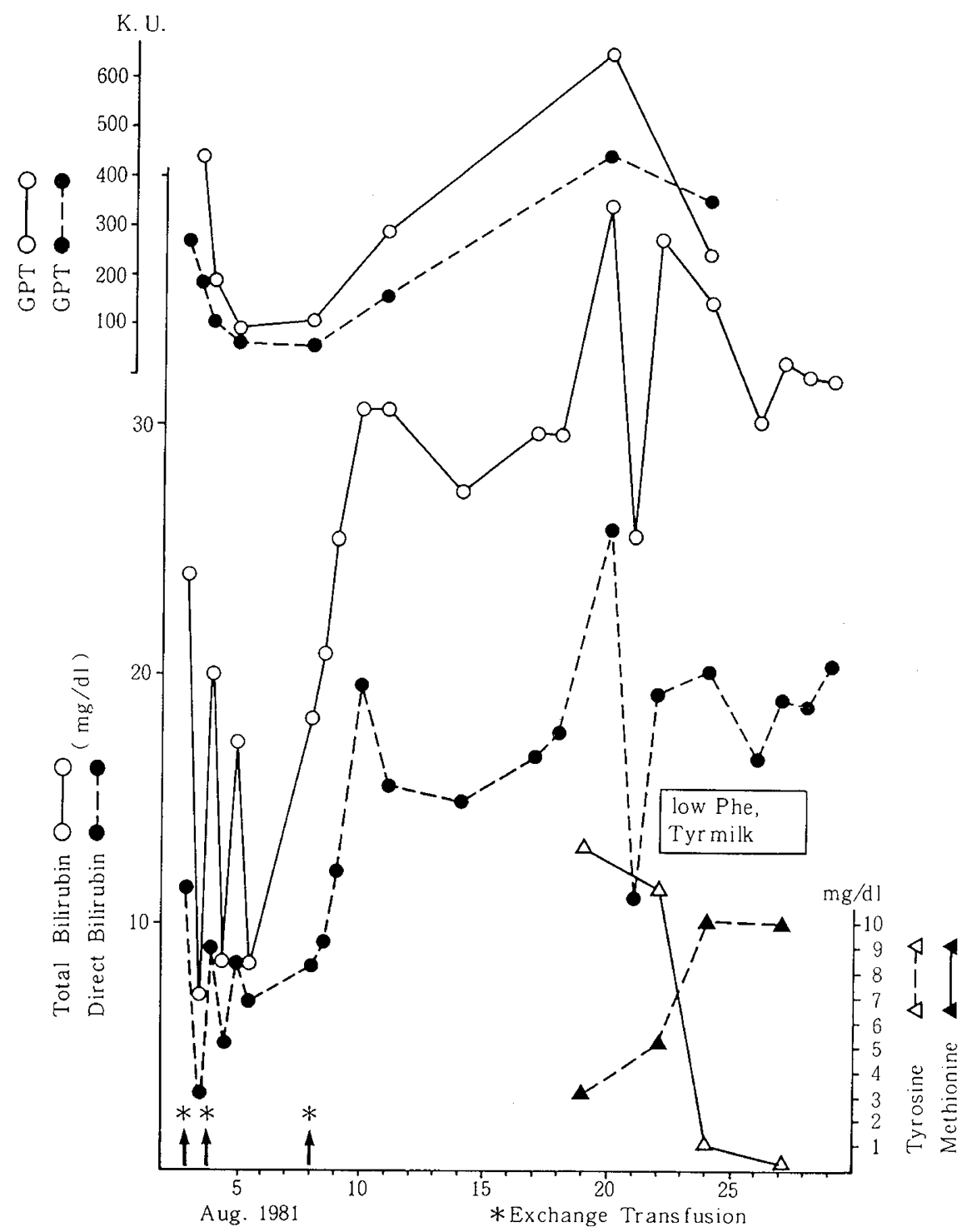

Fig. 1. Graphic summary of clinical course.

Table 1. Abnormal urinary metabolites*

\begin{tabular}{lrcr}
\hline \multicolumn{1}{c}{ Metabolites } & Patient & Normal value & P/N \\
\hline 4-OH-phenylacetate & 15.56 & 0.54 & $(28)$ \\
4-OH-phenyllactate & 64.60 & 1.71 & $(38)$ \\
4-OH-phenylpyruvate & 2.90 & n.d. $\dagger$ & \\
Glycine & 11.65 & 0.38 & $(31)$ \\
Threonine & 5.30 & 0.03 & $(177)$ \\
Tyrosine & 2.17 & 0.034 & $(64)$ \\
Serine & 3.32 & 0.15 & $(22)$ \\
\hline
\end{tabular}

* Relative value for internal std./mg creatinine.

$\dagger$ Not detected.

For TAT assay, frozen tissues were homogenized in 9 vol of $0.14 \mathrm{M} \mathrm{KCl}$ containing $1 \mathrm{mM}$ EDTA and cytosol was obtained by centrifuging at $15,000 \mathrm{~g}$ for $30 \mathrm{~min}$. For p-HPPA oxidase assay, tissues were homogenized in 5 vol of $0.1 \mathrm{M}$ potassium

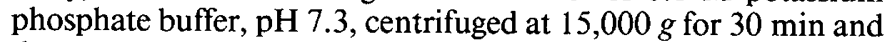
the supernatant was used. For FAH assay, tissues were homogenized in 9 vol of $0.25 \mathrm{M}$ sucrose and high speed-supernatant was obtained by centrifuging at $100,000 \mathrm{~g}$ for $60 \mathrm{~min}$. All procedures were carried out at $0-4^{\circ} \mathrm{C}$.

TAT was determined according to the method of Granner $e t$ al. (10). p-HPPA oxidase was measured by modifying the isotopic method of Fellman et al. (6) with 10 times higher radioactive $p$ hydroxy [carboxy $\left.-{ }^{14} \mathrm{C}\right]$ phenylpyruvate than the original method.
FAH was measured by the method of Edwards and Knox (4, 14), except that the substrate, fumarylacetoacetate, was prepared by homogentisate oxidase from mouse liver. Protein was determined by the method of Lowry et al. (18) using bovine serum albumin as a standard.

\section{RESULTS}

Amino acids and phenolic acids in serum and urine. Serum amino acids, except tyrosine and methionine, were within normal range. Abnormally excreted urinary organic acids and amino acids at diagnosis, summarized in Table 1 , were p-HPPA, $p$ hydroxyphenyllactate, $p$-hydroxyphenyacetate, glycine, threonine, tyrosine, and serine.

Enzyme activities in cytosol of liver and kidney (Table 2). Enzyme activities $\left(\mathrm{nmol} \cdot \mathrm{min}^{-1} \cdot \mathrm{mg}\right.$ protein $\left.{ }^{-1}\right)$ in the patient were compared with those from nine controls in ages from 1-63-yr old. None of the enzyme activities in tissues of the control group showed consistent age-related variations. The high TAT activity of control A was probably due to hepatoma (20). The high activity of liver FAH, 65.3, in control $E$ was derived from unknown reasons. In the patient, TAT and FAH in liver were both decreased to approximately $40-60 \%$ of the median value of control tissues. TAT in kidney was in the range of control values. The most significant reduction of enzyme activities were found in p-HPPA oxidase in liver and FAH in kidney: each 
Table 2. Enzyme activities* in liver and kidney of the patient with tyrosinemia type I and controls

\begin{tabular}{|c|c|c|c|c|c|c|}
\hline \multirow[b]{2}{*}{ Subjects $\dagger$} & \multicolumn{2}{|c|}{ TAT } & \multicolumn{2}{|c|}{ p-HPPA oxidase } & \multicolumn{2}{|c|}{$\mathrm{FAH}$} \\
\hline & Liver & Kidney & Liver & Kidney & Liver & Kidney \\
\hline Control A & $14.3 \ddagger$ & $\ldots$ & 12.9 & $\ldots$ & 15.9 & $\ldots$ \\
\hline Control B & $\ldots$ & $\ldots$ & $\ldots$ & $\ldots$ & 24.3 & $\ldots$ \\
\hline Control C & 4.8 & 0.6 & 14.4 & $\ldots$ & $\ldots$ & $\ldots$ \\
\hline Control D & 2.7 & 0.3 & 8.3 & 1.8 & 24.4 & 12.0 \\
\hline Control E & 5.6 & 0.8 & 12.6 & 3.2 & 65.3 & $\ldots$ \\
\hline Control $\mathrm{F}$ & $\ldots$ & $\ldots$ & 7.2 & 0.8 & & $\ldots$ \\
\hline Control G & 3.1 & 0.7 & $\ldots$ & 1.2 & 26.2 & 12.2 \\
\hline Control H & $\ldots$ & $\ldots$ & $\ldots$ & $\ldots$ & 21.8 & 8.5 \\
\hline Control I & $\ldots$ & $\ldots$ & $\ldots$ & $\ldots$ & $\ldots$ & 7.4 \\
\hline Median & 4.8 & 0.7 & 12.6 & 1.5 & 24.4 & 10.3 \\
\hline Patient median & 1.7 & 0.50 & : 1.4 & 0.28 & 14.7 & 1.4 \\
\hline range & $(1.6,1.8)$ & $(0.47,0.52)$ & $(1.3-1.5)$ & $(0.25-0.29)$ & $(11.2-15.4)$ & $(1.1-1.7)$ \\
\hline & $(2)^{\S}$ & (2) & (3) & (3) & (3) & (4) \\
\hline
\end{tabular}

* Enzyme activities are expressed as $\mathrm{nmol} \cdot \mathrm{min}^{-1} \cdot \mathrm{mg}$ protein ${ }^{-1}$. Abbreviations: see "Abbreviations."

$\uparrow$ Control A, 56-yr-old male with hepatoma.

Control B, 63-yr-old male with meningioma.

Control C, 45-yr-old female with gastric cancer.

Control D, 13-yr-old female with acute myelocytic leukemia.

Control E, 5-yr-old male with neuroblastoma.

Control F, 8-yr-old male with Reye's syndrome.

Control G, 3-yr-old female with purulent meningitis.

Control H, 1-yr-old male with sudden infant death syndrome.

Control I, 5-yr-old male with acute lymphoblastic leukemia.

$\ddagger$ Values are means of duplicate determinations.

${ }^{\S}$ Numbers in parentheses represent number of separate assays when performed.

Table 3. Enzyme properties in liver and kidney

\begin{tabular}{cccccc}
\hline & \multicolumn{2}{c}{$\mathrm{p}$-HPPA oxidase* } & \multicolumn{2}{c}{ FAH* $^{*}$} \\
\cline { 2 - 3 } \cline { 5 - 6 } & Control & Patient & & Control & Patient \\
\hline Liver & $(n=4)$ & $(2)^{\S}$ & & $(n=5)$ & $(4)$ \\
$\mathrm{K}_{\mathrm{m}} \dagger$ & $8.4 \pm 3.9 \ddagger$ & 4.9 & & $0.9 \pm 0.5$ & $1.5 \pm 0.3$ \\
Range & $(5.4-13.7)$ & $(4.1,5.6)$ & $(0.4-1.6)$ & $(1.3-1.9)$ \\
$\mathrm{V}_{\max }{ }^{\prime}$ & $18.0 \pm 10.0$ & 1.7 & $26.4 \pm 17.4$ & $14.3 \pm 1.4$ \\
Range & $(6.7-30.5)$ & $(1.6,1.7)$ & $(14.6-64.7)$ & $(12.9-16.2)$ \\
Kidney & $(n=2)$ & $(1)^{\S}$ & $(n=3)$ & $(2)$ \\
$\mathrm{K}_{\mathrm{m}} \dagger$ & 2.9 & 7.5 & $1.0 \pm 0.1 \dagger$ & 0.7 \\
Range & $(1.5,4.3)$ & $\ldots$ & $(0.9-1.1)$ & $(0.6,0.8)$ \\
$\mathrm{V}_{\max }{ }^{\prime}$ & 1.4 & 0.6 & $14.1 \pm 2.2$ & 1.8 \\
Range & $(0.9,1.9)$ & $\ldots$ & $(12.0-16.3)$ & $(1.7,1.9)$ \\
\hline
\end{tabular}

*Abbreviations: see "Abbreviations."

$\uparrow \mu \mathrm{M}$.

$\ddagger$ Mean $\pm \mathrm{SD}$

${ }^{\$}$ Numbers in parentheses represent number of separate assays when performed.

nmol $\cdot \mathrm{min}^{-1} \cdot \mathrm{mg}$ protein ${ }^{-1}$.

accounted for less than $15 \%$ of the control values. When the $p$ HPPA oxidase activities were determined by deleting the reduced form of 2,6-dichloroindophenol from the standard assay, the activities in both tissues were comparably decreased between the patient and controls (liver, $64 \%$ vs $63-81 \%$ and kidney, $58 \%$ vs $48-68 \%$ ). The kinetic characteristics of the p-HPPA oxidase and FAH were determined using Lineweaver Burke plots. Data are summarized in Table 3 . The $\mathrm{K}_{\mathrm{m}}$ of $\mathrm{p}$-HPPA oxidase for $\mathrm{p}$-HPPA was not different from that of corresponding controls either in liver or kidney. FAH in liver and kidney of the patient also showed no difference from control in terms of $\mathrm{K}_{\mathrm{m}}$ for fumarylacetoacetate. As expected from the specific activities in Table $2, \mathrm{~V}_{\max }$ alone is different between the patient and control groups.

\section{DISCUSSION}

Clinically, the patient took the most severe course observed in other reported cases of hereditary tyrosinemia type I, acute form (16). Dietary treatment with a low phenylalanine-tyrosine formula and supplemented with ascorbate brought no clinical improvement, as is often stated in other reports (11). The ineffectiveness of a low phenylalanine-tyrosine diet made the contention dubious that the defect of tyrosine metabolism was solely in the step of p-HPPA oxidase, although we confirmed the decreased hepatic p-HPPA oxidase in this case.

Gaull et al. (8) found decreased activities of methionine adenosyltransferase and cystathionine $\beta$-synthase, as well as $\mathrm{p}$ HPPA oxidase, in the liver of tyrosinemia type I and concluded that these enzyme deficiencies were probably secondary manifestations of an unknown metabolic defect. Previously, we also reported deficiencies of both p-HPPA oxidase and methionine adenosyltransferase in another case of hereditary tyrosinemia type I (7).

In 1977, Lindblad et al. (17) found succinylacetoacetate and succinylacetone, possible metabolic products of fumarylacetoacetate, in the urine from three patients with hereditary tyrosinemia type I and postulated that a defect of FAH is responsible for these abnormal metabolites. But the presence of these compounds were not reconfirmed by Chalmers and Lawson (3), suggesting that there are heterogenous causes in the pathogenesis of hereditary tyrosinemia type I. Nevertheless, several investigators have identified the FAH deficiency in liver from patients with this disease $(1,11,14)$.

In this study, we demonstrated that p-HPPA oxidase in liver and FAH in kidney were strikingly decreased to the level of onetenth of control values. TAT and FAH in liver, and p-HPPA oxidase in kidney remained approximately $40 \%$ of the control activities. By interpreting these results, we speculate that a specific enzyme defect may reside at two different steps in separate organs: p-HPPA oxidase in liver and FAH in kidney. In other words, it is possible that enzyme defects were multiple and each 
Table 4. The ratios of enzyme activities in liver and kidney $(L /$ K) of controls*

\begin{tabular}{lccc}
\hline & $\begin{array}{c}\text { Fellman et al. } \\
(5,6)\end{array}$ & Zannoni al. $(24)$ & \\
& 18 & $\ldots$ & Present study \\
\hline TAT $\dagger$ & $3.4-5.0$ & $4.0-6.9$ & $4.4-9.0$ \\
p-HPPA oxidase & $\ldots$ & $4.1-4.4$ & 4.6 .0 \\
Homogentisate oxidase & $\ldots$ & $\ldots$ & $2.0-2.6$ \\
FAH & $\ldots$
\end{tabular}

* Abbreviations: see "Abbreviations."

$\dagger$ Soluble fraction only.

defective enzyme was specific to the particular organs. In this context, Scriver and Rosenberg (2) speculated that the original case of Medes' tyrosinosis might have had a tissue-specific enzyme deficiency, a deficiency of renal TAT alone. Our data also suggest that decreased activities of TAT, FAH in liver, and pHPPA oxidase in kidney may be non-specific, considering their relatively mild loss of enzyme activity. Another interesting aspect in our case is that two sequential enzymes, p-HPPA oxidase and $\mathrm{FAH}$, are involved. Similar findings were described for hereditary orotic acidemia (13); however, we are still not sure whether these two enzyme defects account for all of the altered metabolism in our patient.

It has been well known that the major enzymes, TAT, p-HPPA oxidase, and homogentisate oxidase, involved in tyrosine degradation to fumarate and acetate, are present mainly in liver and kidney. In this study, we first demonstrated that FAH is abundantly present in control kidney tissue as well as in liver (Table 2 ). In terms of the subcellular distribution, these enzymes are mostly in cytosol $(5,6,14,24)$. Although TAT is known to be distributed both in cytosol and mitochondria, we measured only cytosolic TAT in our case. The significance of FAH deficiency in kidney remains to be elucidated in tyrosinemia. One may argue that the deficient FAH activity in kidney tissues of our patient resulted from renal dysfunction, but no definite signs of renal failure were noted throughout his disease (blood urea nitrogen, $10.8-14.4 \mathrm{mg} / \mathrm{dl}$ ). As shown in Table 2, controls $\mathrm{D}$ and $\mathrm{I}$, who suffered from severe renal dysfunction with blood urea nitrogen of $46 \mathrm{mg} / \mathrm{dl}$ and $72 \mathrm{mg} / \mathrm{dl}$, respectively, demonstrated more than 5-fold higher FAH activity than the patient. The biologic significance of FAH in normal human kidney has not yet been well studied. When the ratio (liver/kidney) of specific activities in liver and kidney are calculated for these four enzymes, it decreases in the order of TAT, p-HPPA oxidase, homogentisate oxidase, and FAH (Table 4). These results may indicate that FAH plays a more important role than other related enzymes, especially in kidney.

Clinically, tyrosinemia type I must be differentiated from neonatal transient tyrosinemia. Even in the latter, low activity of TAT and p-HPPA oxidase has been hypothesized; however, to date, this has not been confirmed (9). Because our patient was premature and exact age-matched controls were not available in this study, one may argue that the low activity of p-HPPA oxidase was physiologic. But because it was activated to the same degree as that from control tissues we assume that the decreased pHPPA oxidase in our patient's liver is probably not due to prematurity (22). The $K_{m}$ of p-HPPA oxidase and FAH for each substrate were not different from those of corresponding controls for either liver or kidney. This may suggest that the alteration of enzyme properties is not responsible for the enzyme deficiencies, though further examination such as $\mathrm{pH}$ velocity profiles or heat stability is needed.
In conclusion, we describe a case of tyrosinemia type I with rapid fatal course due to hepatic dysfunction. Postmortem study disclosed that activities of p-HPPA oxidase in liver and FAH in kidney were most markedly affected. Though the primary defect is yet unknown, we speculate that the deficient activity of FAH in kidney may play a significant role in the pathogenesis of this disorder.

\section{REFERENCES AND NOTES}

1. Berger, R., Smit, G. P. A., Stoker-de Vries, S. A., Duran, M., Ketting, D., and Wadman, S. K.: Deficiency of fumarylacetoacetase in a patient with hereditary tyrosinemia. Clin. Chim. Acta, 114: 37 (1981).

2. Carson, N. A. J., Biggart, J. D., Bittles, A. H., and Donovan, D.: Hereditary tyrosinemia: clinical, enzymatic, and pathological study of an infant with the acute form of the disease. Arch. Dis. Child., 51: 106 (1976).

3. Chalmers, R. A. and Lawson, A. M.: Organic acidurias due to disorders in other metabolic pathways. In: R. A. Chalmers and A. M. Lawson: Organic Acids in Man. p. 405-445 (Chapman and Hall Ltd. London, New York, 1982).

4. Edwards, S. W. and Knox, W. E.: In: S. P. Colowick and N. O. Kaplan: Methods in Enzymology. Vol. II, p. 298 (Academic Press, New York, 1955).

5. Fellman, J. H., Vanbellinghen, R. T., and Koler, R. D.: Soluble and mitochondrial forms of tyrosine aminotransferase. Relationship to human tyrosinemia. Biochemistry, 8: 615 (1969).

6. Fellman, J. H., Fujita, T. S., and Roth, E. S.: Assay, properties and tissue distribution of p-hydroxyphenylpyruvate hydroxylase. Biochim. Biophys. Acta, 284: 90 (1972).

7. Furukawa, N., Oya, N., Nakajima, F., Kinugasa, A., Mino, M., and Kusunoki, T.: Enzymatic study of an infant with the acute form of hereditary tyrosinemia. Acta Paediatr. Jap., 20: 30 (1978).

8. Gaull, G. E., Rassin, D. K., Solomon, G. E., Harris, R. C., Sturman, J. A.: Biochemical observations on so-called hereditary tyrosinemia. Pediatr. Res., 4: 337 (1970).

9. Goldsmith, L. A.: Tyrosinemia and related disorders. In: J. B. Stanbury and D. G. Fredrickson: The Metabolic Basis of Inherited Disease. p. 287-299 (McGraw-Hill, New York, 1983).

10. Granner, D. K. and Tomkins, G. M. In: H. Tabor and C. W. Tabor: Methods in Enzymology, Vol. XVII A, p. 633 (Academic Press Inc., New York, 1970).

11. Gray, R. G. F., Patrick, A. D., Preston, F. E., and Whitefield, M. F.: Acute hereditary tyrosinemia type I: clinical, biochemical and hematological studies in twins. J. Inher. Metab. Dis., 4: 37 (1981).

12. Halvorsen, S., Pande, H., Locken, A. C., and Gjessing, L. R.: Tyrosinosis: a study of 6 cases. Arch. Dis. Child., 41: 238 (1966).

13. Kelley, W. N.: Hereditary orotic aciduria. In: J. B. Stanbury, J. B. Wyngaarden, K. S. Fredrickson, J. L. Goldstein, M. S. Brown: The Metabolic Basis of Inherited Diseases. p. 1201-1226 (McGraw-Hill, New York, 1983)

14. Kvittingen, E. A., Jellum, E., and Stokke, O.: Assay of fumarylacetoacetate fumarylhydrolase in human liver-deficient activity in a case of hereditary tyrosinemia. Clin. Chim. Acta, 115: 311 (1981).

15. LaDu, B. N.: The enzymatic study in tyrosinemia. Am. J. Dis. Child., 113: 54 (1967).

16. LaDu, B. N. and Gjessing, L. R.: Tyrosinosis and tyrosinemia, In: J. B. Stanbury, J. B. Wyngaarden, D. S. Fredrickson: The Metabolic Basis of Inherited Disease. p. 256-257 (McGraw-Hill, New York, 1978).

17. Lindblad, B., Lindstedt, S., and Steen, G.: On the enzymic defects in hereditary tyrosinemia. Proc. Natl. Acad. Sci. USA, 74: 4641 (1977).

18. Lowry, O. H., Rosebrough, N. J., Farr, A. L., and Randall, R. J.: Protein measurement with the Folin phenol reagent. J. Biol. Chem., 193: 265 (1951).

19. Dr. Matsumoto I.: Research Institute of Medical Mass Spectrometry, Kurume University School of Medicine, Kurume 830, Japan.

20. Pitot, H. C.: Some biochemical essentials of malignancy. Cancer Res., 23: 1474 (1963).

21. Sakai, K. and Kitagawa, T.: An atypical case of tyrosinosis (1-Parahydroxyphenyl lactic acid uria). II. A research on the metabolic block. Jikeikai Med. J., 4: 1 (1957).

22. Scriver, C. R. and Rosenberg, L. E.: Tyrosine. C. R. Scriber and L. E. Rosenberg: In: Amino Acid Metabolism and Its Disorders. p. 338-369 (W. B. Saunders Co., Philadelphia, London, Toronto, 1973)

23. Taniguchi, K. and Gjessing, L. R.: Studies on tyrosinosis: 2. activity of the transaminase, parahydroxyphenyl-pyruvate oxidase and homogentisic-acid oxidase. Br. Med. J., 1: 968 (1965).

24. Zannoni, V. G., Seegmiller, J. E., and LaDu, B. N.: Nature of the defect in alcaptonuria. Nature, 193: 952 (1962).

25. Requests for reprints should be addressed to: Dr. Nobuaki Furukawa, Department of Pediatrics, Kyoto Prefectural University of Medicine, 602, Kyoto, Japan.

26. Received for publication March 31, 1983.

27. Accepted for publication August 12, 1983. 